\title{
Cultivating a Cycle of Trust With Diverse Communities in Practice-Based Research: A Report From PRIME Net
}

\author{
Christina M. Getrich, $P b D^{1}$ \\ Andrew L. Sussman, PbD, MCRP ${ }^{1}$ \\ Kimberly Campbell-Voytal, $P b D$, \\ $\mathrm{RN}^{2}$ \\ Janice Y. Tsob, $P b D^{3}$ \\ Robert L. Williams, MD, MPH \\ Anthony E. Brown, MD, MPH \\ Michael B. Potter, $M D^{3}$ \\ William Spears, $\mathrm{PbD}^{5}$ \\ Nancy Weller, DrPb ${ }^{6}$ \\ Jobn Pascoe, $M D^{5}$ \\ Kendra Scbwartz, MD, MSPH \\ Anne Victoria Neale, PbD, MPH ${ }^{2}$ \\ 'University of New Mexico, Albuquerque, \\ New Mexico \\ ${ }^{2}$ Wayne State University School of Medi- \\ cine, Detroit, Michigan \\ ${ }^{3}$ University of California, San Francisco, \\ San Francisco, California \\ ${ }^{4}$ Baylor College of Medicine, Houston, \\ Texas \\ ${ }^{5}$ Wright State University, Fairborn, Ohio \\ ${ }^{6}$ University of Texas Health Science Center \\ at Houston, Houston, Texas
}

Conflicts of interest: authors report none.

\section{CORRESPONDING AUTHOR}

Christina M. Getrich, PhD

MSC 095040

1 University of New Mexico

Albuquerque, NM 87131-0001

chgetrich@salud.unm.edu

\begin{abstract}
PURPOSE Practice-based research networks (PBRNs) are increasingly seen as important vehicles to translate research into practice, although less is known about the process of engaging diverse communities in PBRN research. The objective of this study was to identify strategies for successfully recruiting and retaining diverse racial/ethnic communities into PBRN research studies.
\end{abstract}

METHODS This collaborative, multisite study engaged 5 of the 8 networks of the PRImary care MultiEthnic Network (PRIME Net) consortium that conducts research with traditionally underrepresented/underserved populations. We used a sequential, qualitative research design. We first conducted 1 key informant interview with each of 24 researchers experienced in recruiting research participants from 5 racial/ethnic communities (African American, Arab/Chaldean, Chinese, Hispanic, and Native American). Subsequently, we conducted 18 focus groups with 172 persons from these communities.

RESULTS Participants' comments indicated that successful recruitment and retention of underrepresented populations in PBRN studies is linked to the overall research process. This process, which we termed the cycle of trust, entailed developing and sustaining relationships of trust during 4 interrelated stages: before the study, during study recruitment, throughout study conduct, and after study completion. Participants identified a set of flexible strategies within each stage and called for close engagement with clinic and community partners.

CONCLUSIONS Our participants suggest that approaches to research that lay a foundation of trust, demonstrate respect for community members, and extend beyond the enrollment and data collection phases are essential to enhance the participation of diverse populations in PBRN research. These findings offer the PBRN community a guide toward achieving this important goal.

Ann Fam Med 2013;550-558. doi:10.1370/afm.1543.

\section{INTRODUCTION}

$\mathrm{N}$ ational leaders in the United States are insisting on more rapid translation of research into practice, greater applicability of research to everyday practice, and inclusion of diverse populations in the research effort. With regard to the last, diverse populations are consistently underrepresented in clinical research studies. ${ }^{1-4}$ Although practice-based research networks (PBRNs) have drawn attention as mechanisms to facilitate the goals of speeding translation of research into practice, less is known about the process of engaging diverse communities in PBRN research.

PBRNs have a long history of working with primary care clinicians to generate research ideas and facilitate study recruitment, ${ }^{5}$ and have also sought to engage, though to a lesser degree, patients and community members in the research process. ${ }^{6}$ They are well positioned to access diverse patient populations and contexts. ${ }^{7}$ Despite this potential, we are not aware of any systematic examinations of how PBRNs engage a wide range of racial/ethnic groups in the research enterprise.

Failure to recruit and enroll diverse racial/ethnic groups into clinical studies hampers our ability to gain a comprehensive understanding of dif- 
ferences among population subgroups and to develop effective services and interventions, ${ }^{4}$ and ultimately jeopardizes social justice and equity in health care. ${ }^{1,8,9}$ There are a number of well-described reasons for underrepresentation of minorities in clinical research, including fear, mistrust, lack of access to medical care, participation-associated costs, scheduling conflicts, employment constraints, geographic distances, and language and/or cultural differences. ${ }^{2-4,10,11}$

Less is known, however, about developing culturally sensitive procedures for recruitment and retention that address the concerns of diverse racial/ethnic groups. ${ }^{12,13}$ Focused research toward these goals offers the promise of more effectively addressing these health disparities. ${ }^{3,8,10,11}$ Strategies to facilitate recruitment of diverse racial/ethnic groups in clinical research in general have been proposed, including forming genuine partnerships, ${ }^{7,11,14}$ fostering open communication, ${ }^{7,11}$ including community representatives on the research team, ${ }^{1,15}$ and involving community members both in developing research agendas and in refining research protocols. ${ }^{16}$ It is not clear, however, how these principles might generalize to the unique contexts of PBRNs, with their need to engage the clinicians and practices serving these communities, as well as the communities and individuals living in them as they seek to recruit and retain diverse groups in their research.

With a national consortium of PBRNs, we gathered data about appropriate ways to engage 5 diverse racial/ ethnic communities in PBRN and clinical research. The objective of this study was to identify strategies for recruiting and retaining (an underexamined aspect of research with diverse communities) a broad spectrum of racially/ethnically diverse primary care patients into clinical research studies. We evaluated these strategies from the perspective of both members of these communities and researchers experienced in conducting research with diverse groups.

\section{METHODS}

This multinetwork study engaged 5 of the 8 networks of the PRImary care MultiEthnic Network (PRIME Net). PRIME Net is a consortium of PBRNs with a mission to conduct research focused on traditionally underrepresented and underserved populations. ${ }^{17-22}$ We identified 5 diverse racial/ethnic communities for this study, reflecting a primary community with which each participating PBRN interacts: African Americans (Southwestern Ohio Ambulatory Research Network [SOAR-Net] $;$ Dayton, Ohio), Arab/Chaldeans (MetroNet; Detroit, Michigan), Chinese (San Francisco Bay Collaborative Research Network [SF Bay $\mathrm{CRN}]_{\text {; }}$ San Francisco, California), Hispanics (Southern
Primary-care Urban Research Network [SPUR-Net]; Houston, Texas), and Navajo, a southwestern group of Native Americans (Research Involving Outpatient Settings Network [RIOS Net]; New Mexico). Each PBRN gained approval for its research protocol from its university's institutional review board; additionally, RIOS Net received approval from the Navajo Nation Human Research Review Board. Our team consisted of 13 investigators from multiple disciplines including medicine (R.L.W., M.B.P., K.S., J.P., A.E.B), public health (R.L.W., A.V.N., K.S., N.W.), nursing (K.C.V., N.W.), medical anthropology (C.M.G., A.L.S., K.C.V.), psychology (J.Y.T., A.V.N.), and sociology (W.S.). We used a sequential, qualitative research design that consisted of key informant interviews and focus groups.

\section{Participant Recruitment and Data Collection}

Researcher Key Informant Interviews

We developed and pilot-tested a key informant interview guide (http://fcm.unm.edu/research/docs/ Trust\%20in\%20Practice-Based\%20Research.Getrich\%20et\%20al.\%202013.pdf) with 3 interviews. Next, each network recruited and interviewed key informants experienced in clinic- and communitybased research with their racial/ethnic community of interest. All of the research team participated in these interviews, drawing on their preexisting relationships with key informants in some cases. Informed consent was obtained at the beginning of the interview. Research team members from each network conducted and digitally recorded the interviews, which lasted between 40 and 110 minutes, in person or over the telephone. Key informants received a $\$ 75.00$ gift card for their participation.

\section{Community Member Focus Groups}

We used findings from the key informant interviews to develop the focus group discussion guide (http:// fcm.unm.edu/research/docs/Trust\%20in\%20PracticeBased\%20Research.Getrich\%20et\%20al.\%202013. pdf). We standardized the guide for use across the 5 networks with a common set of stem questions; however, networks also made minor adjustments to customize the guide to their specific populations with regard to geographic location (urban vs rural) and access to care. Some questions in the guide specifically solicited input on participation in clinic-based research involving primary care clinicians. Each PBRN recruited convenience samples of participants (patients aged 18 years or older who received care in a primary care clinic) from its network, using approaches consistent both with recruitment recommendations made by key informants for that community and with the prior experience of the research team, through churches 
(African Americans and Chaldeans), primary care and community health clinics (Chinese and Hispanics), a clinical and social services center (Arabs), and community meeting halls (Navajo).

Each network conducted a minimum of 3 focus groups; 2 networks, MetroNet and SF Bay CRN, conducted an additional 1 and 2 sessions, respectively. Groups ranged in size from 6 to 10 participants. We used bilingual facilitators or provided translators for focus groups conducted in a language other than English (Arabic, Chaldean, Cantonese, Mandarin, Spanish, and Navajo). Ten groups were conducted principally in English, while 8 were conducted almost exclusively in the non-English languages. Two moderators facilitated each audio-recorded group. After informed consent, participants completed a brief demographic questionnaire. Focus groups lasted 45 to 105 minutes; we provided light refreshments and gave participants $\$ 50$ for their time and expenses.

\section{Data Analysis}

We uploaded digital audio files, field notes, and demographic data to a secure project website. Englishlanguage recordings were transcribed centrally, while in-house translators from each PBRN translated and transcribed audio files in non-English languages. Each network verified and finalized transcripts before importing them into the qualitative coding software NVivo8 (QSR International) for analysis.

\section{Table 1. Key Informants, by Predominant Research Perspective}

\begin{tabular}{lcc}
\hline $\begin{array}{l}\text { Predominant } \\
\text { Research Perspective }\end{array}$ & Number & $\begin{array}{c}\text { Years of Experience, } \\
\text { Median }\end{array}$ \\
\hline Academic & 10 & 20 \\
$\begin{array}{c}\text { Clinical/practice-based } \\
\text { research network }\end{array}$ & 8 & 20 \\
$\begin{array}{l}\text { Community agencyl } \\
\text { nonprofit }\end{array}$ & 6 & 15.5 \\
\hline
\end{tabular}

We used an iterative analytic process to distill the recommended strategies beginning with the key informant interviews. First, each member of the data analysis team (C.M.G., K.C.V., A.L.S.) independently reviewed a common set of 3 key informant transcripts and inductively developed a draft code list. We then refined the code list by applying the draft codes to 2 additional transcripts, discussing differences in the application of codes, adjusting codes as necessary, and reaching the final list by consensus. After all key informant transcripts were coded using this list, we created and distributed summaries for each PBRN that captured themes relevant to each network's racial/ethnic population of interest. Representatives from each PBRN reviewed the summary to confirm its accuracy and completeness. We then created a master summary document that captured key themes across racial/ethnic communities. We followed a similar analytic process for the focus group data analysis.

After finalizing both sets of key informant and focus group summaries, representatives of each network collaborated with the data analysis team to draft an integrated list of recommended strategies for recruiting and retaining diverse primary care patients in research studies. We circulated several rounds of the recommended strategies document to all team members and discussed these during biweekly team conference calls. All 5 PBRN sites approved the final document. In addition, preliminary results were presented to both clinical and community audiences in a variety of settings (ie, clinic staff meetings and meetings at community centers) to solicit feedback and verify findings before and after the project ended. Feedback from these clinician and community stakeholders helped shape the results presented in this article.

\section{RESULTS}

We conducted 1 interview with each of 24 key informants (Table 1) and 18 focus groups with 172 participants (Table 2).

Table 2. Focus Group Participants, by Racial/Ethnic Group

\begin{tabular}{|c|c|c|c|c|c|}
\hline $\begin{array}{l}\text { Racial/Ethnic } \\
\text { Group }\end{array}$ & $\begin{array}{l}\text { Nos. of Groups } \\
\text { (Participants) }\end{array}$ & $\begin{array}{c}\text { English Preferred, \% } \\
\text { (No.) }\end{array}$ & $\begin{array}{c}\text { US Nationality, } \\
\% \text { (No.) }\end{array}$ & $\begin{array}{l}\text { Time Living in US, }{ }^{a} \\
\text { Median (SD), y }\end{array}$ & $\begin{array}{l}\text { Women, \% } \\
\text { (No.) }\end{array}$ \\
\hline African American & $3(30)$ & $100(30)$ & $100(30)$ & NA & $63(17)$ \\
\hline Arab/Chaldean & $4(36)$ & $25(9)$ & $22(8)$ & $16(9.8)$ & $50(18)$ \\
\hline Chinese & $5(47)$ & $11(5)$ & $10(5)$ & $14.5(9.1)$ & $66(31)$ \\
\hline Hispanic & $3(22)$ & $36(8)$ & $68(15)$ & $32(14.7)$ & $68(15)$ \\
\hline Navajo & $3(27)$ & 7 (2) & $100(27)$ & NA & $66(18)$ \\
\hline
\end{tabular}




\section{Cycle of Trust}

Both sets of participants (key informants and focus group members) identified common elements believed to influence success in the recruitment and retention of racial/ethnic minority populations in clinical research studies. With these shared perspectives, we combined results from both sets of participants into a cycle of trust framework (Figure 1) consisting of developing and sustaining relationships of trust during 4 stages: before the study, during study recruitment, throughout study conduct, and after study completion. A consistent and overarching theme that emerged was the importance of viewing the research process as interrelated and continuous across time and studies. Key elements of each stage, and points of intersection, are outlined below. We were able to cull a general set of 7 strategies constituting the 4 research stages across racial/ethnic groups $_{i}$ however, most of these general strategies were expressed differently for each racial/ethnic group based on distinct social contexts, cultural variations, and life experiences (Table 3).

\section{Before the Study}

The first stage in the cycle involved strategies 1 through 3. Participants strongly advocated that researchers build trust with community and clinical partners before study implementation. A Navajo focus group participant stressed the necessity of building trust by asserting, "If someone were to come out into the community... and we didn't know them, but they wanted to ask us some questions, we probably wouldn't be able to be open to them, because...we'd be unsure of them." Navajo and African Americans in particular identified a past history of abusive researcher practices leading to mistrust Suas a hindrance to present-day research participation. As one African American focus group participant noted, "I think we've already been turned off to medical research...[now] we need to be turned on!"

Key informants and focus group participants alike highlighted the importance of assembling a culturally

\begin{tabular}{ccc}
$\begin{array}{c}\text { Age, Median } \\
\text { (Range), y }\end{array}$ & $\begin{array}{c}\text { Education, High } \\
\text { School or More, } \\
\text { \% (No.) }\end{array}$ & $\begin{array}{c}\text { Experienced in } \\
\text { Research, \% (No.) }\end{array}$ \\
\hline $51(26-66)$ & $90(27)$ & $10(3)$ \\
$42(19-84)$ & $53(19)$ & $11(4)$ \\
$58(22-84)$ & $49(23)$ & $32(15)$ \\
$53(31-75)$ & $23(5)$ & $9(2)$ \\
$58(36-78)$ & $N^{b}$ & $18(5)$ \\
\hline
\end{tabular}

\section{Figure 1. The cycle of trust.}

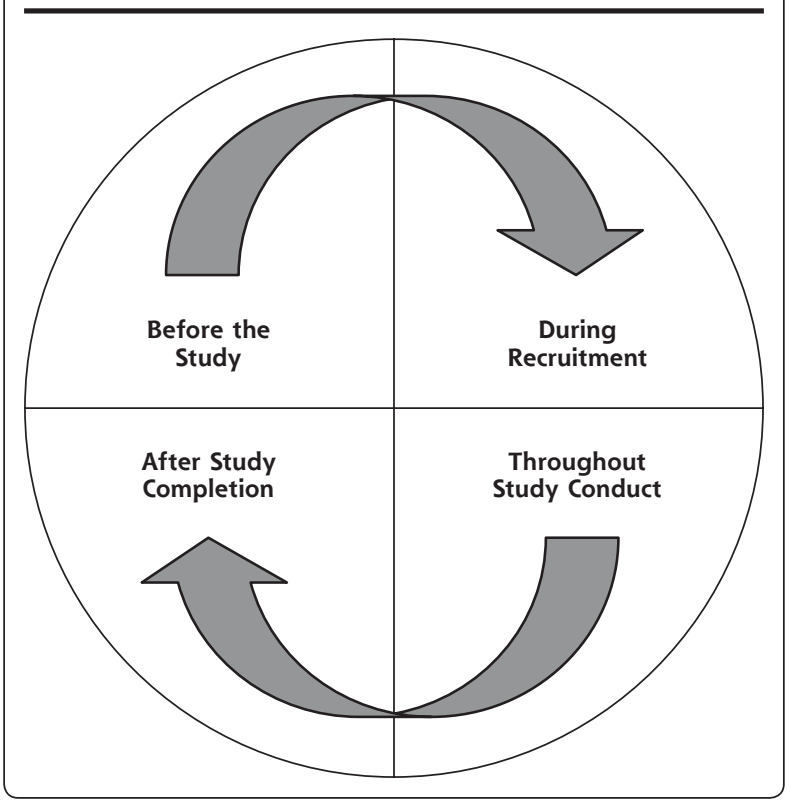

competent research team as a means of cultivating trust. One key informant who works with the Arab/ Chaldean community stated, "The stigma around mental health, suicide, divorce, rape, AIDS/HIV, sexuality...those are very hush-hush things. It requires a skilled, respected, and trusted communicator to address these issues." Participants identified desirable traits for these individuals, such as being bilingual/ bicultural, familiar with cultural norms, and likeable, but also stated that outsiders could be effective as well if they proved their trustworthiness.

Key informant researchers also emphasized the importance of relationship building with clinical partners before study implementation. In addition, they highlighted the importance of identifying a relevant topic for clinicians and developing a feasible research design that meshed well with clinical settings. As one key informant researcher who works with the Chinese community noted,

What is really critical is to spend time in the research design process. Even at that [early] stage...you're going to want to know that the research questions are relevant to the patients and to the clinics. Often they will have really interesting ideas... or they may tell you that this is not relevant and may really alter the way that you develop the project.

\section{During Study Recruitment}

The second stage in the cycle involved strategies 4 and 5. Key informants expressed the need to collaborate with both community and clinical partners to develop flexible approaches to study recruitment. They identified the importance of understanding the clinical context ${ }_{i}$ 
one key informant who conducts studies with Hispanics underscored this point by saying, "[The] number 1 priority is relieving clinician burden. Know how the clinic is organized and how the study affects patient flow." Key informants also talked about the advantages of continually assessing clinic needs throughout the implementation process to ensure a mutually satisfying study. Building trust with clinical partners in these communities is an important element of successful recruitment and retention.

Focus group participants echoed the need for flexible and multiple recruitment strategies. For example, they believed that effective study recruitment entailed the use of various personalized approaches that help to build trust; as one Hispanic participant shared, "having the personal touch really makes a difference." Key informant researchers highlighted some of the specific personal touches that they found to be effective in the communities they served. A researcher working with Arab/Chaldean communities, for instance, noted that they have found it important to have sex concordance between recruiters and participants. A researcher working with the Chinese community shared that it worked well to emphasize family values and highlight the benefits of research to the family and community in their recruitment efforts.

In addition, focus group participants stressed that they would like to be told extensive details about the study while being recruited, such as one African American participant who stated, "Every inch of it needs to be transparent. We need to know who's doing the study, what the study is for, what are the consequences, what are the output, what are they looking for, what do they expect, you know, all those types of things."

\section{Throughout Study Conduct}

The third stage in the cycle involved strategy 6. Participants believed

Table 3. Recommended Strategies for Recruiting and Retaining Diverse Communities in Research

\begin{tabular}{|c|c|}
\hline Views/Strategy & $\begin{array}{l}\text { African Americans } \\
\text { (SOAR-Net) }\end{array}$ \\
\hline \multirow{3}{*}{$\begin{array}{l}\text { General Views } \\
\text { of Research } \\
\text { Participation }\end{array}$} & Implicit distrust in research enterprise \\
\hline & High level of suspicion in "the system" \\
\hline & Sense that research hasn't been beneficial \\
\hline \multirow[t]{2}{*}{$\begin{array}{l}\text { Strategy 1: Trust With } \\
\text { Targeted Partners }\end{array}$} & $\begin{array}{l}\text { Tuskegee study a legacy of distrust (of the government and health } \\
\text { research) }\end{array}$ \\
\hline & Importance of being honest up front and throughout projects \\
\hline \multirow{10}{*}{$\begin{array}{l}\text { Strategy 2: Relevant } \\
\text { Topic and Feasible } \\
\text { Study Design }\end{array}$} & The same general principles apply across groups: \\
\hline & Community \\
\hline & $\begin{array}{l}\text { Focus projects on specific topics of relevance to community mem- } \\
\text { bers (eg, diabetes, hypertension) }\end{array}$ \\
\hline & $\begin{array}{l}\text { Consider community members' motivations for research participa- } \\
\text { tion (eg, desire to learn, advance science, help one's family) }\end{array}$ \\
\hline & $\begin{array}{l}\text { Make research participation accessible and convenient to a wide } \\
\text { spectrum of community members }\end{array}$ \\
\hline & Clinical \\
\hline & Ensure studies are of clinical importance \\
\hline & Identify clinician allies and collaborate with them \\
\hline & $\begin{array}{l}\text { Clinicians with strong relationships with patients best suited to } \\
\text { recruit }\end{array}$ \\
\hline & Reduce the burden of participation for clinicians and clinical staff \\
\hline \multirow{2}{*}{$\begin{array}{l}\text { Strategy 3: A Compe- } \\
\text { tent Research Team }\end{array}$} & Team members should be relatable people \\
\hline & $\begin{array}{l}\text { Transparency in communication is important-research team should } \\
\text { be forthcoming with information }\end{array}$ \\
\hline
\end{tabular}

Strategy 4: Tailored Recruitment Strategies

Recruitment should be personalized

Patient navigators can be used to adapt language in study materials and to successfully recruit families

Strategy 5: Study Implementation

Strategy 6: Tailored Retention Strategies

Strategy 7: Closing the Loop and Sowing the Seeds of Future Research Projects
The same general principles apply across groups:

Buy-in of clinic staff can influence the success of the study Have a designated research person to contact when study-related problems arise

Obtain feedback from clinic staff on study processes

Keep clinicians in the loop (even if not actively part of project)

Find out clinic's approach to recontacting patients

Important to maintain relationships with families (through personal calls)

Participants need to see progress/change

Need to do continuous follow-up, including years beyond the end of the project

Desire for the next generation to know about research results
SOAR-Net = Southwestern Ohio Ambulatory Research Network; SF Bay CRN = San Francisco Bay Collaborative Research Network; SPUR-Net = Southern Primary-care Urban Research Network; RIOS Net = Research Involving Outpatient Settings Network; PI = principal investigator. 


\section{Arab Americans} (MetroNet)

Desire to learn is a potent motivator Recognition of value of prevention-supports research involvement

Suspicion of outsiders-need to establish trust

Key community figures (doctors and religious leaders) influential in brokering trust

\section{Chinese Americans} (SF Bay CRN)

Perceive benefits in gaining knowledge and advancing science

Some fear and uncertainty, and concern about scams

Credibility of the researcher and/ or the research institution important

Leverage trust through doctors or other authority figures

\section{Hispanic Americans}

(SPUR-Net)

Generally positive connotation surrounding research

Desire to help family members and future generations as motivators

High level of trust in credible doctors and community clinics

Fears about immigration status makes trust building essential$$
\text { ... }
$$

Navajo

(RIOS Net)

Desires to learn about health topics and to help people and communities are motivators

Concern about being mistreated as research participants

Initial distrust of researchers (historical legacy of abuse)

Visit to communities is imperative to introduce researchers/ projects and establish trust
Knowing a community member on research team is helpful-people are not as open with strangers

Language ability is important

Person-to-person/word-of-mouth recruitment preferred

Sex concordance between recruiters and participants is importanthusbands may have to give wives permission
Staff should not push too hardpeople should be allowed to make their own decisions

Staff professionalism is important for ensuring privacy

Good bilingual marketing materials are essential

Emphasize family values (highlight benefits of research to family and community)

Tap into social networks (family and community)
Recruiters must be fluen unless participants are acculturated

Staff should have good and regular communication with participants

Personal touch is important (ie, telephone calls from trusted organizations or contacts)

Easier to recruit from within clinic than off the street (minimizes suspicion)
Breaching privacy was a concern when local community residents are part of research team

Local research team member is ultimately held more responsible for the project than the PI

Oral communications are important-word of mouth or radio advertisements

Pamphlets with pictures are useful

Expectation that researchers participate in local events

Projects may need to be adaptable to local events and instabilities

Inquire about overall healthnot just project focus

Staff continuity throughout project is important

Important to disseminate research results to maintain one's reputation

Have an end-of-study event to recognize clinical staff

Staff relationships with partici pants are important (need to have good and regular communication)

Need alternative contact information (many migrate during year)

Desire for progress reports/ regular updates efit the community

Attend festivals and religious celebrations

Help community members access the university
Results need to be disseminated beyond the clinical setting
Help people improve their wellbeing-including beyond the end of the study

Hold local meetings to present meaning of results

Involve community members in dissemination of materials
Highlight Chinese populations' needs to the government 
that the same core recruitment principles would apply for study retention, as encapsulated by an African American focus group participant who said, "The same thing that got me there would keep me there. If it was a cause that I felt drawn to, or I felt passionate about, then I would stay for as long as the trial required."

Study participants expressed the need for personalized communication approaches to achieve high levels of retention in studies. For enhancing collaboration and communication with clinical partners, a key informant researcher who works with the Chinese community advised, "[You need to] send the clinics regular personal updates about what is going on with the study, you know, individualized e-mails so they know you are available, asking them for feedback about how things are going, and being responsive." Continuity of research staff throughout the study is also important to participants.

Focus group participants expressed the same need for personalized attention and frequent communication throughout the study; one African American participant reflected, "I would like not to feel like a number. So the fact that they send a card or give me a call or say, 'It's been so many weeks since the first trial, how are you feeling? How do you feel about what is going on?"'

\section{After Study Completion}

The fourth stage in the cycle involved strategy 7. Both sets of participants reflected on the importance of reporting back research results. Key informants talked about the importance of returning results to maintain researchers' - and more broadly, institutions'-reputations within the communities. A key informant who works with Arab Americans reflected on the impact of previous projects, recalling, "Some Caucasian PIs [principal investigators] interested in minority populations [went] there [and did] this study but never sort of got back...so we got a very bad reputation. I learned the lesson from listening to them... [about] what went wrong previously." Conversely, another key informant working with Arab Americans identified the positive potential of a good reputation, saying, "It's word of mouth, so the people, when you give them back their own feedback on their own results, then they spread that out."

One Navajo focus group participant noted, "[Some] researchers...just come and go. Poke their head in, then it's over. And they're never back to give us the results. They're never really back here to help the people solve the problem." This individual's comment underscores the desire that focus group participants expressed to see some kind of benefit from the research or to have researchers do something to help solve health issues. One Arab/Chaldean participant reflected, "You participate and you never hear about it.
What's the benefit? You put in your effort to benefit. But if you don't hear about it, I don't think you will be encouraged to do it again."

Study participants across sites strongly asserted that study wrap-up activities should not be seen as the endpoint of the research process. In fact, participants noted that future study efforts may be, in part, contingent on how well researchers have ushered past projects through this cycle of trust across all stages. A key informant researcher who works with the Navajo Nation noted, "Make sure that you do follow-up and dissemination as part of your application...you're building trust." This trust then feeds back to the first stage as a researcher goes about trying to develop a new project with community input. A key informant researcher who works with the Arab community joked, "They still call me [and] say, 'When is your next study?' So that's pretty good." How well a given researcher maneuvers through this cycle of trust also has implications for other researchers; as one key informant researcher who works with the Chinese community noted, "[you're] not only building up your own reputation [and] getting yourself known to them, but also building a pathway for future researchers."

\section{DISCUSSION}

This study highlights the critical importance of trust in the participation of underrepresented communities in practice-based health research. Our participants emphasized that establishing and maintaining trust through a set of relationship-building activities, through communications, and through ensuring appropriate return to the community is essential. These observations were consistent across the diverse racial/ethnic communities with whom we spoke and among the researchers experienced in these communities. The circular nature of this trust cultivation, whereby past experience builds future trust, led us to term it the cycle of trust.

There has been a tendency to view the issue of underrepresentation of minority communities in clinical research as a problem of barriers to participation, and the solution as one of overcoming those barriers. ${ }^{23}$ Our work provides a different perspective, highlighting the central role of trust in the engagement of these communities. In support of this view, Wendler et $\mathrm{al}^{3}$ found that when approached, minorities were no less likely to participate in research-and perhaps were even more receptive to participation.

We believe that although these elements of the research effort are important to the engagement of underrepresented minority communities in practicebased health research, they may in fact be universal. The principles of respect, communications, and bidi- 
rectional benefit underlying our findings appear to be increasingly important regardless of the population and might be seen as applicable to nonminority groups.

At the same time, we found that familiarity with and sensitivity to the particular cultural perspectives and experiences of the specific groups being recruited for participation is important.

\section{Application of the Cycle of Trust to PBRN Research}

This central role of trust has been noted in previous work examining underrepresented community members' perspectives on the adequacy of research protections for communities., ${ }^{42,15,24}$ We note as well the parallels between action steps derived from our participants' comments and those of the community-based participatory research and other participatory research models $s^{13,15,25,26}$ that are increasingly featured in PBRN research studies. ${ }^{11,16,27}$

PBRNs are in a unique position to actualize the strategies we outline and to ensure that clinical research more equitably serves the needs of all peoples. Although this position poses great challenges for PBRNs, ${ }^{27}$ the continuity of relationships that are inherent in PBRNs is a valuable foundation for the cycle of trust. PBRNs that are able to infuse into their research culture the principles of respectful relationships, bidirectional communication, and useful return of results will maximize their ability to link clinicians, underrepresented communities, and researchers in meaningful research.

Others have pointed out that the development and nurturing of the cycle of trust takes time and attention. ${ }^{11,16,24}$ The dominant model of research funding does not account for the resources needed to nurture this trust, especially before and after the data collection phases-the first and fourth stages in the cycle of trust presented herein. The effort and resources required to develop community applications of research results - to close the loop-as part of the cycle of trust are well outside the scope of the current research funding model. Another implication of these findings related to trust is the need for research participants' protections to engage at a community, rather than an individual, level. ${ }^{24,28,29}$ Current review processes do not necessarily include communities as active partners in the development of research topics and protocols. Our findings suggest that new models for funding and participant protection are needed if participation of underrepresented groups in clinical research is to be expanded and maintained.

\section{Study Strengths and Limitations}

Our study has several strengths and limitations. The breadth of the PRIME Net consortium permitted us to examine the question of research participation with a diverse group of communities, including some not often included in consideration of this issue. Indeed, previous research in this area has focused more narrowly on the minority groups that have been federally defined as underrepresented (eg, African Americans and Hispanics) with less consideration of Asian Americans, Native Americans, and other relatively small minority subgroups (eg, Arab Americans). ${ }^{8}$ Our research did not include all communities that might be considered underrepresented, however, and the generalizability of our findings to other communities is unknown. Nevertheless, the consistency of our findings across the groups does suggest broader generalizability. The triangulation of findings from both researchers and community members could also be seen as support for generalizability. Another limitation that should be kept in mind is the wide variety of individual perspectives and experiences within any given community or racial/ethnic group. Although our emphasis was on identifying broad principles related to research participation, sensitivity to the diversity of personal perspectives and experiences is important.

\section{Implications}

Increasing the participation of diverse populations in clinical research continues to be a challenge. Our participants suggest that approaches to research that (1) lay a foundation for a trusting relationship among researchers, clinicians, and members of underrepresented communities, (2) demonstrate respect for the community members, and (3) extend beyond the enrollment and data collection phases are essential to enhance the participation of diverse populations in PBRN clinical research. These findings provide guidance on culturally sensitive procedures for research recruitment and retention of diverse minority groups and offer the PBRN community a guide toward achieving this important goal.

To read or post commentaries in response to this article, see it online at www.annfammed.org/content/11/6/550.

Key words: patient recruitment; trust; minority groups; populations, underserved; primary care; practice-based research

Submitted September 7, 2012; submitted, revised, January 29, 2013; accepted February 21, 2013.

Funding support: This study was supported by a grant from the National Institutes of Health, National Center for Minority Health and Health Disparities (RC1 MD004692), Principal Investigator: A.V. Neale.

Previous presentations: "National Collaboration to Develop Best Practices for Recruiting Ethnically Diverse Patients into PBRN Studies: A PRIME Net Report"-poster presented at the AHRQ Practice Based Research Network Annual Conference, Bethesda, MD, June 16, 
2010. "Key Informant and Focus Group Suggestions for Involving Ethnically Diverse Patients in Primary Care Studies: A PRIME Net Report"poster presented at the AHRQ Practice Based Research Network Annual Conference, Bethesda, MD, June 23, 2011. "Strategic Considerations for Recruiting and Retaining Ethno-racial Minorities in Primary Care Research: A PRIME Net Report"-poster presented at the 39th North American Primary Care Research Group (NAPCRG) Annual Meeting, Banff, Alberta, Canada, November 15, 2011.

\section{References}

1. Seifer SD, Michaels M, Collins S. Applying community-based participatory research principles and approaches in clinical trials: forging a new model for cancer clinical research. Prog Community Health Partnersh. 2010;4(1):37-46.

2. Sheikh A. Why are ethnic minorities underrepresented in U.S. research studies? PLoS Med. 2006;3(2):e49.

3. Wendler D, Kington R, Madans J, et al. Are racial and ethnic minorities less willing to participate in health research? PLOS Med. 2006;3(2):e19.

4. Yancey AK, Ortega AN, Kumanyika SK. Effective recruitment and retention of minority research participants. Annu Rev Public Health. 2006;27:1-28.

5. Howerton MW, Gibbons MC, Baffi CR, et al. Provider roles in the recruitment of underrepresented populations to cancer clinical trials. Cancer. 2007;109(3):465-476.

6. Westfall JM, VanVorst RF, Main DS, Herbert C. Community-based participatory research in practice-based research networks. Ann Fam Med. 2006;4(1):8-14.

7. Tapp H, Dulin M. The science of primary health-care improvement: potential and use of community-based participatory research by practice-based research networks for translation of research into practice. Exp Biol Med (Maywood). 2010;235(3):290-299.

8. Hussain-Gambles M, Atkin K, Leese B. Why ethnic minority groups are under-represented in clinical trials: a review of the literature. Health Soc Care Community. 2004;12(5):382-388.

9. Mosenifar Z. Population issues in clinical trials. Proc Am Thorac Soc. 2007;4(2):185-187, discussion 187-188.

10. Khaliq W, Gross M, Thyagarajan B, Jones-Webb R. What motivates minorities to participate in research? Minn Med. 2003;86(10):39-42.

11. UyBico SJ, Pavel S, Gross CP. Recruiting vulnerable populations into research: a systematic review of recruitment interventions. J Gen Intern Med. 2007;22(6):852-863.

12. Ford JG, Howerton MW, Bolen S, et al. Knowledge and access to information on recruitment of underrepresented populations to cancer clinical trials. Evid Rep Technol Assess Summ. 2005;(122):1-11.

13. Lai GY, Gary TL, Tilburt J, et al. Effectiveness of strategies to recruit underrepresented populations into cancer clinical trials. Clin Trials. 2006;3(2):133-141.

14. Adderley-Kelly B, Green PM. Strategies for successful conduct of research with low-income African American populations. Nurs Outlook. 2005;53(3):147-152.

15. Larkey LK, Gonzalez JA, Mar LE, Glantz N. Latina recruitment for cancer prevention education via community based participatory research strategies. Contemp Clin Trials. 2009;30(1):47-54.
16. Robinson JM, Trochim WMK. An examination of community members', researchers' and health professionals' perceptions of barriers to minority participation in medical research: an application of concept mapping. Ethn Health. 2007;12(5):521-539.

17. Kong AS, Williams RL, Rhyne R, et al; PRIME Net Clinicians. Acanthosis nigricans: high prevalence and association with diabetes in a practice-based research network consortium-a PRImary care Multi-Ethnic network (PRIME Net) study. J Am Board Fam Med. 2010;23(4):476-485.

18. Kroth PJ, McPherson L, Leverence R, et al; Prime Net Consortium. Combining Web-based and mail surveys improves response rates: a PBRN study from PRIME Net. Ann Fam Med. 2009;7(3):245-248.

19. Leverence RR, Williams RL, Potter M, et al on behalf of PRIME Net clinicians. Chronic non-cancer pain: a siren for primary care-a report from the PRImary care MultiEthnic Network (PRIME Net). J Am Board Fam Med. 2011;24(5):551-561.

20. Leverence RR, Williams RL, Pace W, et al; PRIME Net Consortium. Context of clinical care: the case of hepatitis $C$ in underserved communities - a report from the Primary Care Multiethnic Network (PRIME Net) Consortium. J Am Board Fam Med. 2009;22(6):638-646.

21. Rhyne R, Sussman AL, Fernald D, Weller N, Daniels E, Williams RL; PRIME Net Clinicians. Reports of persistent change in the clinical encounter following research participation: a report from the Primary Care Multiethnic Network (PRIME Net). J Am Board Fam Med. 2011;24(5):496-502.

22. Williams RL, McPherson L, Kong A, Skipper B, Weller N. Internetbased research training in a practice-based research network consortium: a report on a project on acanthosis nigricans from PRIME Net. J Am Board Fam Med. 2009;22(4):446-452.

23. Walsh C, Ross LF. Are minority children under- or overrepresented in pediatric research? Pediatrics. 2003;112(4):890-895.

24. Williams RL, Willging CE, Quintero G, Kalishman S, Sussman AL, Freeman WL; RIOS Net Members. Ethics of health research in communities: perspectives from the southwestern United States. Ann Fam Med. 2010;8(5):433-439.

25. Minkler M, Wallerstein N. Community-Based Participatory Research for Health: From Process to Outcomes. 2nd ed. San Francisco, CA: Jossey-Bass; 2008.

26. Israel BA, Eng E, Schulz AJ, Parker EA, Satcher D. Methods in Community-Based Participatory Research for Health. San Francisco, CA: Jossey-Bass; 2005.

27. Williams RL, Shelley BM, Sussman AL; RIOS Net clinicians. The marriage of community-based participatory research and practicebased research networks: can it work? A Research Involving Outpatient Settings Network (RIOS Net) study. J Am Board Fam Med. 2009;22(4):428-435.

28. Weijer C. Protecting communities in research: philosophical and pragmatic challenges. Camb Q Healthc Ethics. 1999;8(4):501-513.

29. Weijer C, Goldsand G, Emanuel EJ. Protecting communities in research: current guidelines and limits of extrapolation. Nat Genet. 1999;23(3):275-280. 